\title{
Lack of associations between two previously identified susceptible single nucleotide polymorphisms of interleukin-23 receptor gene and ankylosing spondylitis: a replication study in a Chinese Han population
}

\author{
Bang-ping Qian, Jun Jiang, Ming-liang Ji, Bin Wang, Yang Yu and Yong Qiu*
}

\begin{abstract}
Background: The human leukocyte antigen (HLA)-B27 gene is considered to be a major gene associated with predisposition to ankylosing spondylitis (AS); however, studies have demonstrated that non-HLA-B27 genes also contribute substantially to the susceptibility to AS. Two single nucleotide polymorphisms (SNPs), rs1004819 and rs10889677, of the interleukin-23 receptor (IL-23R) gene have been shown to be associated with AS susceptibility in European populations. However, ethnicity factors contribute to population splitting and genetic variation, and ethnic-specific genetic association studies are needed to validate these associations in patients from different ethnic backgrounds. This study therefore aimed to replicate the associations between these two SNPs and AS susceptibility in a Chinese Han population.

Methods: A total of 195 AS patients and 203 normal controls were recruited in this study. Two IL-23R gene SNPS, rs 1004819 and rs10889677 were selected. Genotyping was performed in all subjects using the TaqMan probe method. Genotype and allele frequencies were compared between AS patients and normal controls by $x^{2}$ tests.

Results: There were no significant differences in either the genotype frequencies (TT 36.4\%, TC 48.7\% and CC 14.9\% in AS patients; TT 35.0\%, TC 50.0\% and CC 15.0\% in normal controls) or allele frequencies (T 60.8\% and C 39.2\% in AS patients; T $60.0 \%$ and C 40.0\% in normal controls) of rs 1004819 between AS patients and normal controls ( $P$ > 0.05). In addition, both the genotype frequencies (AA 51.3\%, AC 43.1\% and CC 5.6\% in AS patients; AA 57.6\%, AC $35.5 \%$ and CC 6.9\% in normal controls) and allele frequencies (A 72.8\% and C 27.2\% in AS patients; A 75.4\% and C $24.6 \%$ in normal controls) of rs 10889677 were also comparable between AS patients and normal controls $(P>0.05)$.

Conclusions: This study found no evidence for an association between either of the two previously identified AS-susceptibility IL-23R SNPs (rs1004819 and rs10889677) and onset of AS, indicating a possible difference in pathogenesis of AS between Chinese and European patients.
\end{abstract}

Keywords: Interleukin-23 receptor, Gene, Single nucleotide Polymorphism, Ankylosing spondylitis

\footnotetext{
* Correspondence: scoliosis2002@sina.com

Department of Spine Surgery, The Affiliated Drum Tower Hospital of Nanjing University Medical School, Nanjing, China
} 


\section{Background}

Ankylosing spondylitis (AS) is an autoimmune-related disease characterized by chronic inflammations and gradual ossifications of the spine and sacroiliac joints [1]. Substantial evidence suggests that genetic predisposition has a significant impact on individual susceptibility to AS [2]. Although the human leukocyte antigen (HLA)B27 gene is considered to be a primary gene associated with predisposition to AS and confers disease susceptibility, it is unable to explain all cases of AS and its contribution to the overall genetic predisposition is only $20-30 \%$ [3]. Increasing evidence suggests that other, non-HLA-B27 genes also play crucial roles in AS susceptibility [4-6].

The etiology of AS is characterized by aberrant regulations of both the adaptive and innate immune responses [7], suggesting that inflammatory mediators involved in the regulations of immunological reactions could be potential candidate genes. The interleukin-23 receptor (IL-23R) is a member of the hematopoietin receptor superfamily, and constitutes a specific component of the heterodimeric receptor for the cytokine IL-23 [8]. IL23R plays a key role in the differentiation of CD4 T-cell into TH17 lymphocytes, which mediate inflammations in several animal models of autoimmunity $[9,10]$. IL-23R gene polymorphisms may thus be implicated in susceptibility to human autoimmune diseases, such as AS [11].

A recent genome-wide association study reported that the IL-23R gene conferred susceptibility to AS [12], while IL-23R gene variation was responsible for $9 \%$ of the population-attributable risks of AS [12]. The associations between IL-23R gene polymorphisms and AS susceptibility have been confirmed in European populations by genetic association studies [13-15], though the genotype distributions may differ among patients with different ethnic backgrounds [16]. Ethnic-specific genetic association studies are therefore needed to validate the associations between IL-23R gene polymorphisms and AS susceptibility. The aim of this study was to reevaluate the identified associations between two IL-23R gene single nucleotide polymorphisms (SNPs), rs1004819 and rs10889677, and AS susceptibility in a Chinese Han population.

\section{Methods}

\section{Subjects}

The study population consisted of 195 sequential unrelated AS patients (183 men and 12 women) and 203 age- and gender-matched normal controls (178 men and 25 women) recruited from January 2008 to January 2012. All the subjects investigated were of Chinese Han ethnicity. All the AS patients were recruited from the outpatient clinic of the affiliated Drum Tower Hospital of Nanjing University Medical School, while the normal controls were recruited from the medical control center for the healthy population at the hospital. The average age of the AS patients was 32 years (range, 21-53 years), and all patients satisfied the modified 1984 New York criteria [17]. The normal controls were healthy subjects with no autoimmune or musculoskeletal disease, with an average age of 37 years (range, 26-57 years). One hundred and ninety-two AS patients (98.5\%) were HLA-B27-positive and all the normal controls were HLA-B27-negative.

Ethical approval was obtained from the research ethics committee of the medical school of Nanjing University and informed consent for DNA analysis was obtained from all subjects.

\section{Genotyping}

Genomic DNA was extracted from peripheral blood leukocytes using genomic DNA isolation kits (Promega, Madison, WI, USA) according to the manufacturer's instructions. Two IL-23R SNPs (rs1004819 and rs10889 677) were selected for analysis. Genotyping was performed using the TaqMan Probe method with an ABI 7500 Real-time PCR system (Applied Biosystems, Foster City, CA, USA). The primers were designed by Primer Premier 5.0 and are listed in Table 1. The polymerase chain reaction system consisted of $5 \mu \mathrm{l} 2 \times$ TaqMan Master Mix, $0.5 \mu \mathrm{l}$ of each primer $(10 \mathrm{nmol} / \mathrm{l}), 0.25 \mu \mathrm{l}$ of each probe $(10 \mathrm{nmol} / \mathrm{l}), 2 \mu \mathrm{l}$ DNA sample and $1.5 \mu \mathrm{l}$ of sterile deionized water. The mixture was incubated for $5 \mathrm{~min}$ at $94^{\circ} \mathrm{C}$, followed by 35 cycles of $94^{\circ} \mathrm{C}$ for $30 \mathrm{~s}, 58^{\circ} \mathrm{C}$ (for rs1004819) or $60^{\circ} \mathrm{C}$ (for rs 10889677 ) for $30 \mathrm{~s}, 72^{\circ} \mathrm{C}$ for $1 \mathrm{~min}$, and a final extension at $72^{\circ} \mathrm{C}$ for $7 \mathrm{~min}$. Of these samples, $10 \%$ were tested twice to validate the genotyping results, with $100 \%$ reproducibility.

\section{Statistical analysis}

Statistical analysis was performed using SPSS software (version 16.0, SAS, Inc, Chicago, IL, USA). The genotype and allelic frequencies in AS patients and normal controls were compared using $\mathrm{X}^{2}$ tests. $\mathrm{P}<0.05$ was considered to be statistically significant.

Table 1 Sequences of primers and probes for SNP rs1004819 and rs10889677

\begin{tabular}{ccc}
\hline SNP & Products & Sequence \\
\hline rs1004819 & Top primer & 5-CACTGACCTGCTTATGCTGTGA-3 \\
& Bottom primer & 5-TTATAGCAGCACAAGCATTCTAGGA-3 \\
& Probe1-FAM & FAM-TCTTACTATGCTATCTGC-MGB \\
& Probe2-HEX & HEX-TCTTACTGTGCTATCTG-MGB \\
rs10889677 & Top primer & 5-CGGGAGCTCCATGCCTTT-3 \\
& Bottom primer & 5-CACCTTCGGACCTTAATTCTCTAA-3 \\
& Probe1-FAM & FAM-TCTGCCTAATTCT-MGB \\
& Probe2-HEX & HEX-CTTCTGCCTCATTTC-MGB \\
\hline
\end{tabular}


Table 2 Allele and genotype frequencies of SNP rs1004819 and rs10889677 in ankylosing spondylitis patients and normal controls

\begin{tabular}{cccccc}
\hline SNP & $\begin{array}{c}\text { Genotype } \\
\text { and Allele }\end{array}$ & $\begin{array}{c}\text { AS patients } \\
\text { N (\%) }\end{array}$ & $\begin{array}{c}\text { Normal } \\
\text { controls N (\%) }\end{array}$ & X2 & P \\
\hline rs1004819 & TT & $71(36.4 \%)$ & $71(35.0 \%)$ & 0.09 & 0.96 \\
& TC & $95(48.7 \%)$ & $101(50.0 \%)$ & & \\
& CC & $29(14.9 \%)$ & $31(15.0 \%)$ & & \\
& T & $237(60.8 \%)$ & $243(60.0 \%)$ & 0.07 & 0.79 \\
rs10889677 & C & $153(39.2 \%)$ & $163(40.0 \%)$ & & \\
& AA & $100(51.3 \%)$ & $117(57.6 \%)$ & 2.46 & 0.29 \\
& AC & $84(43.1 \%)$ & $72(35.5 \%)$ & & \\
& CC & $11(5.6 \%)$ & $14(6.9 \%)$ & & \\
& A & $284(72.8 \%)$ & $306(75.4 \%)$ & 0.67 & 0.41 \\
& C & $106(27.2 \%)$ & $100(24.6 \%)$ & & \\
\hline
\end{tabular}

\section{Results}

The genotype frequencies of these two SNPs did not deviate significantly from the Hardy-Weinberg equilibrium in either the AS patients or controls.

The genotype frequencies for rs1004819 were TT $36.4 \%$, TC $48.7 \%$ and CC $14.9 \%$ in AS patients, and TT $35.0 \%$, TC $50.0 \%$ and CC $15.0 \%$ in normal controls. The allele frequencies were $\mathrm{T} 60.8 \%$ and $\mathrm{C} 39.2 \%$ in AS patients, and $\mathrm{T} 60.0 \%$ and $\mathrm{C} 40.0 \%$ in normal controls (Table 2). Neither the genotype nor the allele frequencies of rs1004819 differed significantly between AS patients and controls $(\mathrm{P}>0.05)$. The genotype frequencies for rs 10889677 were AA $51.3 \%$, AC $43.1 \%$ and CC $5.6 \%$ in AS patients, and AA 57.6\%, AC $35.5 \%$ and CC $6.9 \%$ in normal controls. The allele frequencies were A $72.8 \%$ and C $27.2 \%$ in AS patients, and A $75.4 \%$ and C 24.6\% in normal controls (Table 2). The genotype and allele frequencies of rs10889677 were also comparable between AS patients and normal controls $(\mathrm{P}>0.05)$.

\section{Discussion}

A substantial proportion of AS genetic susceptibility is known to be encoded by non-HLA genes [5], among which the IL-23R gene has been reportedly associated with the onset of AS in European populations in previous genetic association studies [13-15]. The IL-23R
SNPs rs1004819 and rs10889677 have both been found to confer risks of AS susceptibility in British [13], Hungarian [14] and Portuguese populations [15]; however, ethnic factors contribute greatly to population splitting and genetic variation and genotype distributions may differ significantly among different ethnic groups [16]. The SNP rs1004819 is an A/G variation in these European populations, but a $\mathrm{C} / \mathrm{T}$ variation in the Chinese Han population. Additionally, although rs10889677 is an $\mathrm{A} / \mathrm{C}$ variation in both European and Chinese Han populations, the allele frequency distribution of this SNP differs significantly between these populations, according to the results of previous European studies (Table 3). Data obtained from the International Hapmap Project (http:// hapmap.ncbi.nlm.nih.gov/) also demonstrated wide variations in allele frequencies for these two SNPs between different races. The associations between these two SNPs and AS susceptibility demonstrated in European populations thus need to be confirmed in the Chinese Han population.

The IL-23R gene encodes an important cytokine receptor in the Th17 subset of T lymphocytes [18,19], and IL-23R, together with IL-12R $\beta 1$, comprises the IL-23 receptor complex in IL-23-responsive cells [20]. IL-23 is one of the major regulators of innate and adaptive immunities [8]. It stimulates a unique CD4+ inflammatory T-cell characterized by secretion of IL-17, tumor necrosis factor and IL-6, which are strongly associated with proinflammatory responses and severe autoimmunity [8]. These conclusions suggest a possible involvement of the IL-23/IL-23R pathway in the etiology of AS. SNP rs1004819 and SNP rs10889677 are located in the intronic region and 3'-untranslated (3'-UTR) region of the IL-23R gene, respectively [7]. rs1004819 may exert its influence by regulating differential splicing of IL-23R mRNA, while rs10889677 may lead to variation in the 3'-UTR region, which could be associated with reduced binding of IL-23R mRNA [14]. Both these variations may have functional consequences for the IL-23R pathway and could provide a possible explanation for the associations between these two variants and AS susceptibility in European populations.

Despite the positive associations between these two SNPs and AS in European populations, neither rs100 4819 nor rs10889677 was found to be related to AS

Table 3 Allele frequencies of SNP rs10889677 in European and Chinese Han populations

\begin{tabular}{|c|c|c|c|c|c|c|c|c|}
\hline \multirow[b]{2}{*}{ Allele } & \multicolumn{4}{|c|}{ Ankylosing spondylitis patients (\%) } & \multicolumn{4}{|c|}{ Normal controls (\%) } \\
\hline & A & $C$ & Number & $P^{*}$ & A & C & Number & $P *$ \\
\hline British [12] & $36 \%$ & $64 \%$ & 1818 & 0.000 & $28.5 \%$ & $71.5 \%$ & 1331 & 0.000 \\
\hline Hungarian [13] & $34.5 \%$ & $65.5 \%$ & 206 & 0.000 & $31 \%$ & $69 \%$ & 235 & 0.000 \\
\hline Portuguese [14] & $28 \%$ & $72 \%$ & 358 & 0.000 & $36 \%$ & $64 \%$ & 285 & 0.000 \\
\hline Chinese Han & $72.8 \%$ & $27.2 \%$ & 195 & & $75.4 \%$ & $24.6 \%$ & 203 & \\
\hline
\end{tabular}

*compared with Chinese Han population. 
susceptibility in the current study. The genotype and allele frequencies of both SNPs were similar in AS patients and controls, indicating that neither variation in the IL23R gene was relevant to the etiology of AS. These results suggest that the mechanism responsible for AS may differ between Chinese and European patients, and that AS in Chinese patients may develop through a mechanism independent of these two IL-23R gene variants. Our results support the idea that different disease mechanisms exist in different ethnic populations [16], and a different predisposition gene may be involved in the IL-23/IL-23R signaling pathway in Chinese AS patients. However, we only investigated two SNPs in our study, and therefore cannot completely exclude a role for IL-23R gene in the development of AS in Chinese populations. Further studies including other SNPs that cover the IL-23R gene are necessary to clarify its true role in AS susceptibility.

\section{Conclusions}

In conclusion, the results of this study differed substantially from those of previous European studies. We suggest that this discrepancy can be attributed to racial differences, indicating the need to perform genetic association studies in different ethnic populations to identify race-specific predisposition genes. However, the results of genetic association studies may also differ within races and may produce falsenegative or false-positive results as a result of selection bias of the samples. Thus further studies in the Chinese Han population, including a larger sample size, are also required to confirm the effects of the SNP rs1004819 and SNP rs10889677 on the development of AS.

\section{Competing interests}

The authors declare that they have no competing interests.

\section{Authors' contributions}

BPQ and JJ drafted the manuscript. MLJ carried out the genetic association study and the statistical analysis. BW and YY recruited the patients and participated in the design of this study. BPQ and YQ supervised this study and critically revised the manuscript. All the authors have read and approved the final manuscript.

\section{Acknowledgements}

The authors would like to thank the Development of Medical Technology Key Project (Nanjing, China, ZKX10008) and Medical Technology

Development Project (Nanjing, China, YKK09100) for their financial supports.

Received: 7 November 2012 Accepted: 10 June 2013

Published: 17 June 2013

\section{References}

1. Brown MA, Laval SH, Brophy S, Calin A: Recurrence risk modelling of the genetic susceptibility to ankylosing spondylitis. Ann Rheum Dis 2000, 59:883-886.

2. Reveille JD: Recent studies on the genetic basis of ankylosing spondylitis. Curr Rheumatol Rep 2009, 11:340-348.

3. Santos FP, Bastos E, Ligeiro D, Mourao AF, Chaves R, Trindade H, Guedes-Pinto H, Branco JC: Genetic basis of ankylosing spondylitis. Acta Reumatol Port 2007, 32:243-252.
4. Gunal EK, Sarvan FO, Kamali S, Gul A, Inanc M, Carin M, Konice M, Aral O, Ocal L: Low frequency of HLA-B27 in ankylosing spondylitis patients from Turkey. Joint Bone Spine 2008, 75:299-302.

5. Laval SH, Timms A, Edwards S, Bradbury L, Brophy S, Milicic A, Rubin L, Siminovitch KA, Weeks DE, Calin A, et al: Whole-genome screening in ankylosing spondylitis: evidence of non-MHC genetic-susceptibility loci. Am J Hum Genet 2001, 68:918-926.

6. Brown MA: Breakthroughs in genetic studies of ankylosing spondylitis. Rheumatology (Oxford) 2008, 47:132-137.

7. Rueda B, Orozco G, Raya E, Fernandez-Sueiro JL, Mulero J, Blanco FJ, Vilches C, Gonzalez-Gay MA, Martin J: The IL23R Arg381Gln non-synonymous polymorphism confers susceptibility to ankylosing spondylitis. Ann Rheum Dis 2008, 67:1451-1454.

8. Parham C, Chirica M, Timans J, Vaisberg E, Travis M, Cheung J, Pflanz S, Zhang R, Singh KP, Vega F, et al: A receptor for the heterodimeric cytokine IL-23 is composed of IL-12Rbeta1 and a novel cytokine receptor subunit, IL-23R. J Immunol 2002, 168:5699-5708.

9. Bettelli E, Oukka M, Kuchroo VK: T(H)-17 cells in the circle of immunity and autoimmunity. Nat Immunol 2007, 8:345-350.

10. Langrish CL, McKenzie BS, Wilson NJ, de Waal Malefyt R, Kastelein RA, Cua DJ: IL-12 and IL-23: master regulators of innate and adaptive immunity. Immunol Rev 2004, 202:96-105.

11. Safrany $E$, Melegh B: Functional variants of the interleukin-23 receptor gene in non-gastrointestinal autoimmune diseases. Curr Med Chem 2009, 16:3766-3774.

12. Burton PR, Clayton DG, Cardon LR, Craddock N, Deloukas P, Duncanson A Kwiatkowski DP, McCarthy Ml, Ouwehand WH, Samani NJ, et al: Association scan of 14,500 nonsynonymous SNPs in four diseases identifies autoimmunity variants. Nat Genet 2007, 39:1329-1337.

13. Karaderi T, Harvey D, Farrar C, Appleton LH, Stone MA, Sturrock RD, Brown MA, Wordsworth P, Pointon JJ: Association between the interleukin 23 receptor and ankylosing spondylitis is confirmed by a new UK case-control study and meta-analysis of published series. Rheumatology (Oxford) 2009, 48:386-389.

14. Safrany E, Pazar B, Csongei V, Jaromi L, Polgar N, Sipeky C, Horvath IF, Zeher M, Poor G, Melegh B: Variants of the IL23R gene are associated with ankylosing spondylitis but not with Sjogren syndrome in Hungarian population samples. Scand J Immunol 2009, 70:68-74.

15. Pimentel-Santos FM, Ligeiro D, Matos M, Mourao AF, Sousa E, Pinto P, Ribeiro A, Sousa M, Barcelos A, Godinho F, et al: Association of IL23R and ERAP1 genes with ankylosing spondylitis in a Portuguese population. Clin Exp Rheumatol 2009, 27:800-806.

16. Lee YH, Choi SJ, Ji JD, Song GG: Associations between interleukin-23R polymorphisms and ankylosing spondylitis susceptibility: a meta-analysis . Inflamm Res 2012, 61:143-149.

17. van der Linden S, Valkenburg HA, Cats A: Evaluation of diagnostic criteria for ankylosing spondylitis. A proposal for modification of the New York criteria. Arthritis Rheum 1984, 27:361-368.

18. Wilson NJ, Boniface K, Chan JR, McKenzie BS, Blumenschein WM, Mattson JD, Basham B, Smith K, Chen T, Morel F, et al: Development, cytokine profile and function of human interleukin 17-producing helper T cells. Nat Immunol 2007, 8:950-957.

19. McKenzie BS, Kastelein RA, Cua DJ: Understanding the IL-23-IL-17 immune pathway. Trends Immunol 2006, 27:17-23.

20. Hunter CA: New IL-12-family members: IL-23 and IL-27, cytokines with divergent functions. Nat Rev Immunol 2005, 5:521-531.

doi:10.1186/1471-2474-14-190

Cite this article as: Qian et al:: Lack of associations between two previously identified susceptible single nucleotide polymorphisms of interleukin-23 receptor gene and ankylosing spondylitis: a replication study in a Chinese Han population. BMC Musculoskeletal Disorders 2013 14:190. 